\title{
BIODISPONIBILIDADE DE ÁCIDOS FENÓLICOS
}

Daniela Moura de Oliveira e Deborah Helena Markowicz Bastos*

Departamento de Nutrição, Faculdade de Saúde Pública, Universidade de São Paulo, Av. Dr. Arnaldo, 715, 01246-904 São Paulo - SP, Brasil

Recebido em 31/8/10; aceito em 15/12/10; publicado na web em 25/3/11

PHENOLIC ACIDS BIOAVAILABILITY. The daily intake of phenolic compounds does not necessarily reflect the dose at which they reach the physiological targets in the organisms. The biological activity of phenolic compounds metabolites found in blood, organs and target tissues, as a result of digestive and hepatic activity, may differ from those of the native forms of the substances. This review discusses the absorption and metabolism of phenolic acids, a class of phenolic compounds abundant in food, and the methodologies used for evaluation of bioavailability.

Keywords: phenolic acids; bioavailability; biomarkers.

\section{INTRODUÇÃO}

A ingestão insuficiente de compostos bioativos (CBAs) constitui componente de risco para as doenças crônicas não transmissíveis (DCNT) ${ }^{1,2}$ Estes compostos interferem em alvos fisiológicos específicos, modulando a defesa antioxidante, defesa frente a processos inflamatórios e mutagênicos, os quais estão relacionados a várias doenças e não há dúvida de que sejam essenciais para a manutenção da saúde. CBAs podem ser provenientes de produtos de origem animal (ácido graxo da família ômega 3, ácidos graxos conjugados), vegetal (carotenoides, fitoesterois, terpenos, compostos fenólicos) ou micro-organismos.

CBAs de vegetais (fitoquímicos) compreendem uma grande variedade de classes de compostos químicos com diferentes propriedades físico-quimicas (polaridade, solubilidade, capacidade de formar pontes de hidrogênio, potencial de oxidorredução) que irão determinar tanto o tipo como a eficiência de atividade, assim como o meio e a estrutura celular em que podem atuar.

Compostos fenólicos são abundantes em frutas, vegetais e alimentos derivados dos mesmos, que são consistentemente associados à redução no risco de doenças cardiovasculares, câncer e outras doenças crônicas. ${ }^{3}$ A capacidade dessas substâncias em sequestrar radicais livres e metais pró-oxidantes (ação antioxidante) explica, em parte, esta associação. Evidências recentes sugerem que estes compostos possam atuar por meio de outros mecanismos além da capacidade antioxidante, como a modulação da atividade de diferentes enzimas como telomerase, lipoxigenase e cicloxigenase, interações com receptores e vias de transdução de sinais, regulação do ciclo celular, entre outras, essenciais para a manutenção da homeostase dos organismos vivos. ${ }^{4}$

Para que um composto químico possa exercer atividade biológica, deve atingir o alvo fisiológico numa concentração mínima que determine tanto esse efeito biológico quanto o mecanismo de ação. A ingestão diária de CBAs não necessariamente reflete a dose em que atingirá o alvo fisiológico, o que explica, em parte, a falta de correlação entre os dados epidemiológicos e estudos de intervenção.

*e-mail: dmbastos@usp.br
Visto que estes compostos são reconhecidos pelo organismo como xenobióticos, ${ }^{2}$ estimulando os mecanismos de detoxificação e defesa antioxidante, a concentração fisiológica dos mesmos é relativamente restrita e a biodisponibilidade constitui importante fator de controle. Isso explica a relação entre o consumo diário de compostos fenólicos, que atinge alguns gramas e as baixas concentrações (micromoles) desses compostos nos organismos.

A complexidade para a definição de biomarcadores de exposição a estes compostos é um dos principais fatores que dificultam se atribuir fator de risco ou proteção à saúde em função da ingestão de alimentos fontes de compostos fenólicos. Biomarcadores, neste contexto, correspondem a "uma propriedade observável de um organismo, a qual indica mudanças em componentes celulares ou bioquímicos, em sua estrutura ou função, e que pode ser medida em sistemas biológicos". ${ }^{5}$ O estabelecimento de biomarcadores é essencial para a compreensão da absorção, transporte e metabolismo de um determinado CBA que produz um determinado efeito, em determinado alvo fisiológico (tecido) e em concentração estabelecida.

A validação e o desenvolvimento de biomarcadores dependem do conhecimento de fatores que envolvem a liberação do CBA da matriz do alimento, a absorção, metabolismo, distribuição e excreção, enfim, todo o caminho e transformações que ocorrem com estes compostos.

Os compostos fenólicos representam uma grande variedade de substâncias caracterizadas pela presença de um ou mais anéis aromáticos ligados a pelo menos um radical hidroxila e/ou outros substitutos, e podem ser divididos de acordo com o número de anéis fenólicos e com as estruturas às quais estão ligados. ${ }^{4}$ Os grupos de compostos fenólicos mais abundantes nos alimentos são os flavonoides, os ácidos fenólicos e as lignanas. ${ }^{3,46}$ Existem diversos artigos sobre os efeitos dos compostos fenólicos em sistemas biológicos in vitro. No entanto, a maioria não considera a biodisponibilidade e metabolização destes compostos e, desta forma, muitos dos efeitos observados nestes estudos não necessariamente ocorrem in vivo. Ademais, muitas vezes são utilizados padrões puros dos compostos fenólicos, em concentrações muito superiores àquelas encontradas nos alimentos. ${ }^{1,7,8}$

$\mathrm{O}$ organismo não apresenta mecanismos específicos para o acúmulo ou retenção dos compostos fenólicos a curto prazo, ao contrário do que acontece com algumas vitaminas e minerais. ${ }^{8}$ Eles 
são reconhecidos e tratados pelo organismo da mesma forma que os xenobióticos, sendo metabolizados de forma a serem rapidamente excretados. ${ }^{2,8}$ Os metabólitos encontrados no sangue, órgãos e tecidos alvo, como resultado das atividades digestiva e hepática, podem diferir das formas nativas das substâncias com relação à atividade biológica. ${ }^{9}$

Além disso, os compostos fenólicos mais comuns nos alimentos nem sempre são os mais ativos biologicamente, por diferentes razões, como a baixa atividade intrínseca, baixa absorção intestinal ou rápida metabolização e excreção. ${ }^{10}$

Os flavonoides, em especial a quercetina, as catequinas e as isoflavonas constituem os compostos fenólicos sobre os quais as informações sobre a absorção e metabolismo são mais abundantes na literatura. ${ }^{8,10,11}$ Os ácidos clorogênicos e demais ácidos fenólicos foram menos estudados até o momento, apesar da sua abundância em frutas e vegetais e contribuição para o pool de ingestão desta classe de substâncias.

Embora haja consenso de que os ácidos clorogênicos sejam importantes constituintes da dieta e representem boa parte da ingestão de compostos fenólicos, os dados disponíveis atualmente são insuficientes para que se estabeleçam ingestões dietéticas referência (IDRs) para os mesmos, pois seu metabolismo e biodisponibilidade ainda não estão totalmente esclarecidos. ${ }^{12}$ Os ácidos clorogênicos são ácidos fenólicos, subclasse de uma categoria mais ampla de metabólitos secundários de plantas, denominados compostos fenólicos ou ainda polifenóis. ${ }^{13}$

Esta revisão aborda a rota de absorção dos principais ácidos fenólicos presentes em alimentos de origem vegetal consumidos na dieta ocidental e os metabólitos formados, tema que constitui, hoje em dia, um gargalo para explicar a modulação de processos que podem diminuir o risco de doenças pela ingestão de alimentos funcionais e compostos bioativos.

\section{CLASSIFICAÇÃO QUÍMICA DOS ÁCIDOS FENÓLICOS}

Os ácidos fenólicos apresentam um grupo funcional carboxila e são divididos em duas classes: os ácidos hidroxibenzoicos e os hidroxicinâmicos. ${ }^{4}$ Os primeiros são componentes das complexas estruturas dos taninos hidrolisáveis e são menos abundantes nos vegetais consumidos pelos humanos. ${ }^{14}$ Os ácidos hidroxicinâmicos estão presentes em vários alimentos e bebidas de origem vegetal, como o café, erva mate, maçã, ameixa e outras frutas, crucíferas, cereais, entre outros. ${ }^{15}$ Exemplos desta classse de compostos são o ácido cafeico, $p$-cumárico, ferúlico e sinápico que, na maioria dos alimentos, se encontram esterificados ao ácido quínico, ácido tartárico ou carboidratos e derivados (Figura 1) ${ }^{8,16,17}$ Estes ácidos hidroxicinâmicos também podem ser encontrados na forma livre em alimentos, como o tomate e a cerveja. ${ }^{18}$

Os ácidos clorogênicos (CGAs) são formados pela esterificação do ácido quínico com um dos seguintes ácidos trans-cinâmicos: o ácido cafeico (3,4-di-hidroxicinamico), o ferúlico (3-metoxi, 4-hidróxi), sinápico (3,5-dimetóxi, 4-hidróxi) ou o p-cumárico (4-hidróxi). ${ }^{19,20}$ Podem ser classificados de acordo com o tipo, número e posição dos resíduos acila: mono ésteres (ácidos cafeiolquínicos, CQA; cumaroilquínicos, $p$ CoQA e feruloilquínicos, FQA); di (diCQA), tri (triCQA) e tetra ésteres (tetraCQA) e ainda ésteres mistos dos ácidos cafeico e ferúlico (ácidos cafeiol-feruloilquínicos, CFQA) ${ }^{20}$ Os mais comuns e conhecidos são os mono ésteres do ácido cafeoilquínico, principalmente o ácido 5-O-cafeoilquínico (5-CQA). Inicialmente, o 5-CQA era designado como 3-CQA ou mesmo ácido clorogênico, no entanto, estas denominações caíram em desuso e são desaconselhadas pela IUPAC. ${ }^{21}$ As fórmulas estruturais dos principais ácidos hidroxicinâmicos, ácido quínico e 5-CQA estão representadas na Figura 1.

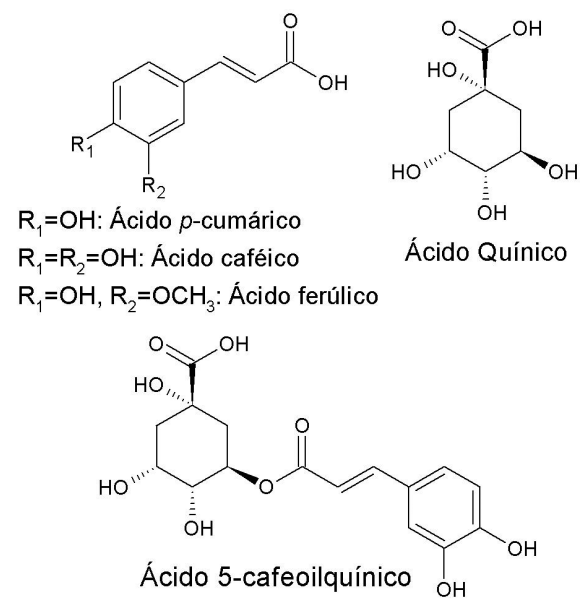

Figura 1. Fórmula estrutural do ácido 5-CQA e dos ácidos que compõem os CGAs

A principal fonte de ácidos clorogênicos na dieta ocidental, de acordo com algumas revisões publicadas sobre o assunto, é o café. ${ }^{15}$ No entanto, outras bebidas de consumo regional, como o chimarrão, preparado com a erva mate, (Ilex paraguariensis), constituem a principal fonte dietética desses compostos na dieta. ${ }^{22}$

Os mono ésteres 3, 4 e 5-CQA correspondem a aproximadamente $10 \%$ da matéria seca dos grãos verdes de café (Coffea canephora $)^{15}$ e a $5 \%$ da massa seca das folhas da erva mate. ${ }^{23}$ Consumidores da bebida podem ter uma ingestão diária de até $1 \mathrm{~g}$ de ácidos clorogênicos, uma vez que uma xícara $(200 \mathrm{~mL})$ de café pode conter de 70 a $350 \mathrm{mg}$ dos mesmos $^{15}$ e uma cuia de chimarrão $(500 \mathrm{~mL})$ cerca de $1,5 \mathrm{~g}$ de fenólicos totais, ${ }^{24,25}$ dos quais $226 \mathrm{mg}$ correspondem ao ácido 5-CQA. ${ }^{26}$ As frutas que contêm as maiores quantidades (mirtilo, kiwi, cereja, maçã, ameixa) apresentam de 500 mg a 2 g de ácidos clorogênicos por kilo da fruta fresca. ${ }^{27}$

\section{BIODISPONIBILIDADE DOS ÁCIDOS FENÓLICOS}

Biodisponibilidade é um termo proveniente da farmacologia e define a fração da dose administrada de uma substância que atinge a circulação sistêmica e a velocidade com que este processo ocorre. ${ }^{28}$ Esta definição abrange vários processos integrados: liberação da substância da matriz, absorção pelo organismo, distribuição, metabolismo e excreção. Tratando-se de alimentos, a biodisponibilidade é definida como a proporção de um nutriente ou substância do alimento que é digerida, absorvida e metabolizada e é, frequentemente, denominada biodisponibilidade relativa. ${ }^{4}$

Vários fatores alteram a biodisponibilidade de compostos bioativos presentes nos alimentos: a complexidade da matriz alimentícia, a forma química do composto de interesse, estrutura e quantidade de outros compostos ingeridos concomitantemente (fatores exógenos) e ainda o tempo de trânsito intestinal, esvaziamento gástrico, metabolismo do composto e grau de conjugação, possíveis interações com proteínas na circulação sanguínea e tecidos, composição da microflora intestinal e o perfil genético do indivíduo (fatores endógenos). ${ }^{8,11}$ Avaliados em conjunto, estes fatores respondem pelas variações intra e inter-individuais na biodisponibilidade de uma determinada substância. ${ }^{2}$

As primeiras evidências, embora indiretas, da absorção dos ácidos clorogênicos e de outros compostos fenólicos são provenientes de estudos que observaram um aumento na capacidade antioxidante do plasma após o consumo de alimentos ricos nestes compostos. ${ }^{10}$ Evidências adicionais foram obtidas por meio da quantificação das concentrações plasmáticas e/ou urinárias de ácidos clorogênicos após 
o consumo de alimentos com quantidades conhecidas dos mesmos ou da suplementação com os compostos isolados. ${ }^{29-34}$ Estes trabalhos utilizaram principalmente cromatografia líquida de alta eficiência (CLAE) com detecção eletroquímica, UV-Vis arranjo de diodos e detectaram baixas concentrações ou mesmo a ausência destes compostos no plasma e urina, sugerindo que sejam metabolizados após a ingestão.

A hifenação de detectores do tipo espectrômetro de massas aos sistemas de CLAE trouxe grandes avanços para este campo de estudos por permitir a identificação e/ou caracterização dos metabólitos formados após a ingestão, ${ }^{5,8,35-42}$ pois permite a análise de quantidades diminutas e é capaz de fornecer um diagnóstico da estrutura química dos compostos. ${ }^{21}$

\section{ABSORÇÃO E METABOLISMO DOS ÁCIDOS FENÓLICOS}

Ensaios em animais com infusão gástrica in situ de 5-CQA e outros ácidos hidroxicinâmicos isolados (ácidos ferúlico, $p$-cumárico e cafeico) indicam que a absorção inicia no estômago, onde uma pequena parcela é absorvida intacta. ${ }^{32,43}$ A presença de 5-CQA - e nenhum outro metabólito - foi detectada no plasma de ratos wistar, após a ingestão de 5-CQA isolado, indicando que o mesmo seria absorvido intacto no estômago. ${ }^{43}$ Ácidos fenólicos não metabolizados também foram detectados no plasma obtido da veia porta de ratos, após a infusão gástrica de diferentes compostos, na seguinte ordem de concentração: $p$-cumárico $>$ ferúlico $>$ cafeico $>5$-CQA. ${ }^{32}$ Outro ensaio em ratos, empregando o ácido 1,5-dicafeoilquínico, também identificou pequenas quantidades no plasma após a ingestão. ${ }^{40}$

A absorção dos ácidos clorogênicos no trato gastrointestinal proximal é inferior à dos ácidos hidroxicinâmicos livres. A mucosa gatrointestinal humana não possui esterases capazes de hidrolisar os ácidos esterificados, o que reduz significativamente a eficiência da absorção dos ácidos clorogênicos no lúmen gástrico e no intestino delgado. ${ }^{14,34,35,44}$ Em indívíduos com ileostomia, foi demonstrado que $33 \%$ de um total de 2,8 mmol ( $1 \mathrm{~g}$ ) de ácidos clorogênicos (isômeros 3,4, e 5-CQA) foram absorvidos no estômago e intestino delgado, enquanto a absorção do ácido cafeico livre, administrado na mesma dose de 2,8 mmol (500 mg), foi de 95\%. ${ }^{30}$ Resultados semelhantes foram encontrados em experimentos com animais. ${ }^{29,38}$

Os compostos não absorvidos no estômago seguem para o intestino delgado, onde os ácidos hidroxicinâmicos livres provenientes dos alimentos são rapidamente absorvidos. ${ }^{30,45}$ Em cultura de células intestinais humanas Caco-2, observou-se que o fluxo transepitelial do 5-CQA é significativamente menor que o fluxo do ácido cafeico que, por sua vez, é menor que o do ácido ferúlico, ${ }^{46} \mathrm{o}$ que pode ser explicado, em parte, pela via de transporte dos compostos através das membranas celulares: os ácidos clorogênicos são absorvidos apenas por transporte paracelular, enquanto os ácidos hidroxicinâmicos livres são absorvidos também por transporte ativo mediado por transportadores de ácidos monocarboxílicos (MCT).$^{32}$ Estes transportadores estão presentes na mucosa gastrointestinal e em diversos tecidos corporais ${ }^{47} \mathrm{e}$, portanto, poderiam participar também do transporte dos ácidos fenólicos em tecidos alvo. ${ }^{17}$

O ácido ferúlico é bem absorvido na parte proximal do intestino. ${ }^{32,45}$ Em ratos, a concentração máxima no plasma deste ácido fenólico intacto e de metabólitos foi atingida após $30 \mathrm{~min}$ da ingestão, e a excreção urinária representou aproximadamente $40 \%$ da dose ingerida na forma do composto puro. ${ }^{48}$

A Figura 2 ilustra os possíveis mecanismos de absorção dos ácidos clorogênicos e dos ácidos hidroxicinâmicos livres.

Com relação ao ácido cafeico, em ratos que receberam uma dose única do composto puro $(700 \mu \mathrm{mol} / \mathrm{kg})$, foram detectados os ácidos cafeico, ferúlico e seus metabólitos sulfatados e glicuronados $30 \mathrm{~min}$

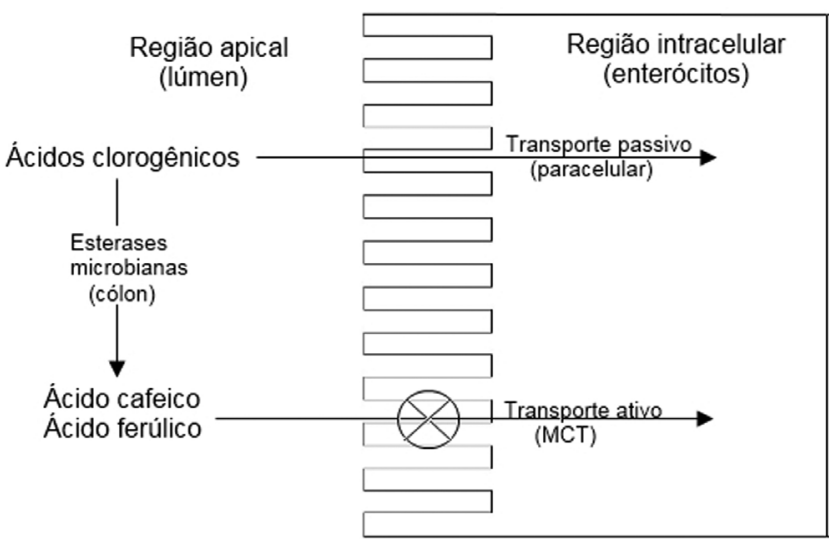

Figura 2. Possível rota de absorção dos ácidos clorogênicos e ácidos hidroxicinâmicos livres

após a ingestão, sendo que a concentração máxima no plasma foi observada após $2 \mathrm{~h} \cdot{ }^{29}$ Os ácidos hidroxicinâmicos livres representam uma pequena parcela do total de compostos fenólicos ingeridos a partir da dieta. De fato, os ácidos hidoxicinâmicos presentes nos alimentos encontram-se principalmente na forma esterificada. ${ }^{20}$

Apesar da taxa de absorção inferior à dos ácidos hidroxicinâmicos livres, ácidos clorogênicos foram detectados intactos no plasma e/ ou urina de humanos e animais após consumo na forma de 5-CQA isolado ${ }^{30,38,39}$ ou de alimentos que apresentam alta concentração destes compostos, como café ${ }^{41,49}$ e ameixa. ${ }^{37}$ Após a ingestão de café por voluntários sadios, foram detectados três ácidos monocafeoilquínicos (3, 4 e 5-CQA) e três dicafeoilquínicos no plasma. ${ }^{41}$ A concentração plasmática de CGA total foi em média 7,66 $\mu \mathrm{mol} / \mathrm{L}$ e dois picos de concentração foram identificados, entre 30 e 60 min e entre 90 e 240 min após a ingestão do café.

Por outro lado, outros trabalhos não conseguiram detectar ácidos clorogênicos no plasma ou urina após o consumo de fenólicos isolados ou alimentos ricos nestes compostos. ${ }^{29,33}$ É provável que os ácidos clorogênicos presentes no plasma e na urina tenham sido hidrolisados durante o tratamento das amostras, visto que a enzima $\beta$-glicuronidase proveniente do molusco Helix pomatia, utilizada nestes estudos para hidrolisar as amostras, é capaz de degradar não só a ligação entre o ácido glicurônico e os ácidos fenólicos, mas também clivar a ligação éster entre o ácido quínico e os ácidos hidroxicinâmicos. ${ }^{10,41,49}$

Uma pequena parte dos ácidos clorogênicos é absorvida sem hidrólise e aproximadamente $1 \%$ dos ácidos clorogênicos ingeridos são encontrados intactos na urina de humanos ${ }^{30,39} \mathrm{e}$ animais. ${ }^{38}$ A maior parte é metabolizada e absorvida no cólon, onde estes compostos sofrerão hidrólise por esterases de origem microbiana e subsequente absorção ou metabolização adicional dos ácidos fenólicos livres (quínico, cumárico, cafeico e ferúlico). ${ }^{34-36,38,39,44}$

Após a absorção, os ácidos clorogênicos e os ácidos hidroxicinâmicos livres podem sofrer ação de enzimas da fase II na mucosa intestinal e posteriormente no fígado ou outros tecidos, formando conjugados sulfatados, glicuronados e/ou metilados, pela ação das sulfotransferases, UDP-glicotransferases e catecol-o-metiltransferases, respectivamente. ${ }^{8,50}$ Estas conjugações representam um processo metabólico de detoxificação comum a muitos xenobióticos, que facilita a eliminação biliar e urinária pelo aumento da hidrofilicidade dos compostos. ${ }^{4}$

Ainda, a flora microbiana do cólon exerce um papel essencial no metabolismo dos ácidos clorogênicos e de compostos fenólicos em geral. Após a clivagem da ligação éster, os ácidos livres podem seguir por duas rotas: absorção pela mucosa intestinal e passagem para a corrente sanguínea (na forma livre ou após conjugação por enzimas 
da fase II) ou podem permanecer no cólon e sofrer metabolização adicional pela microflora. ${ }^{7}$ A maior parte dos CGAs ingeridos é encontrada no plasma e na urina na forma de metabólitos formados pela ação da microflora e posterior metabolização tecidual, sendo os mais abundantes os ácidos hipúrico, hidroxipúrico, $m$-cumárico, ferúlico, isoferúlico, hidroxifenilpropiônico, hidroxibenzoico e vanílico. . $^{35,36,38,41,42}$

O ácido cafeico proveniente da clivagem dos ácidos cafeoilquínicos pode ser encontrado livre na corrente sanguínea, ${ }^{33}$ mas a maior parte da parcela absorvida está na forma de conjugados glicuronados, sulfatados ou como ácido ferúlico e isoferúlico, resultantes da metilação do ácido cafeico. ${ }^{35}$ Os principais derivados do ácido ferúlico, proveniente do ácido cafeico ou da clivagem dos ácidos feruoilquínicos, são os conjugados sulfatados e sulfoglicuronados. . $^{48,51}$

Da parcela dos ácidos hidroxicinâmicos (cafeico, ferúlico e $p$ cumárico) que não é absorvida e permanece no cólon, são originados derivados hidroxilados do ácido fenilpropiônico (3,4 di-hidroxifenilpropiônico, 3 e 4 hidroxifenilpropiônico) por ação da microflora colônica, por meio de reações de hidrogenação e desidroxilação, assim como se origina o ácido $m$-cumárico a partir da desidroxilação do ácido cafeico. ${ }^{38,42}$

O ácido fenilpropiônico e os hidroxifenilpropiônicos são absorvidos e, após $\beta$-oxidação nos tecidos, dão origem aos ácidos benzoicos e hidroxibenzoicos, que podem então ser conjugados com a glicina formando o ácido hipúrico e hidroxipúrico ${ }^{33,38}$ (Figura 3). O ácido hipúrico também pode ser formado a partir do ácido quínico, que após sofrer aromatização pelas bactérias do cólon também dá origem ao

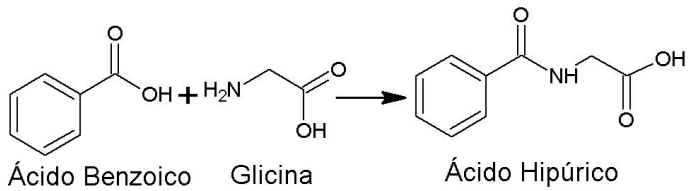

Figura 3. Síntese do ácido hipúrico a partir do ácido benzoico

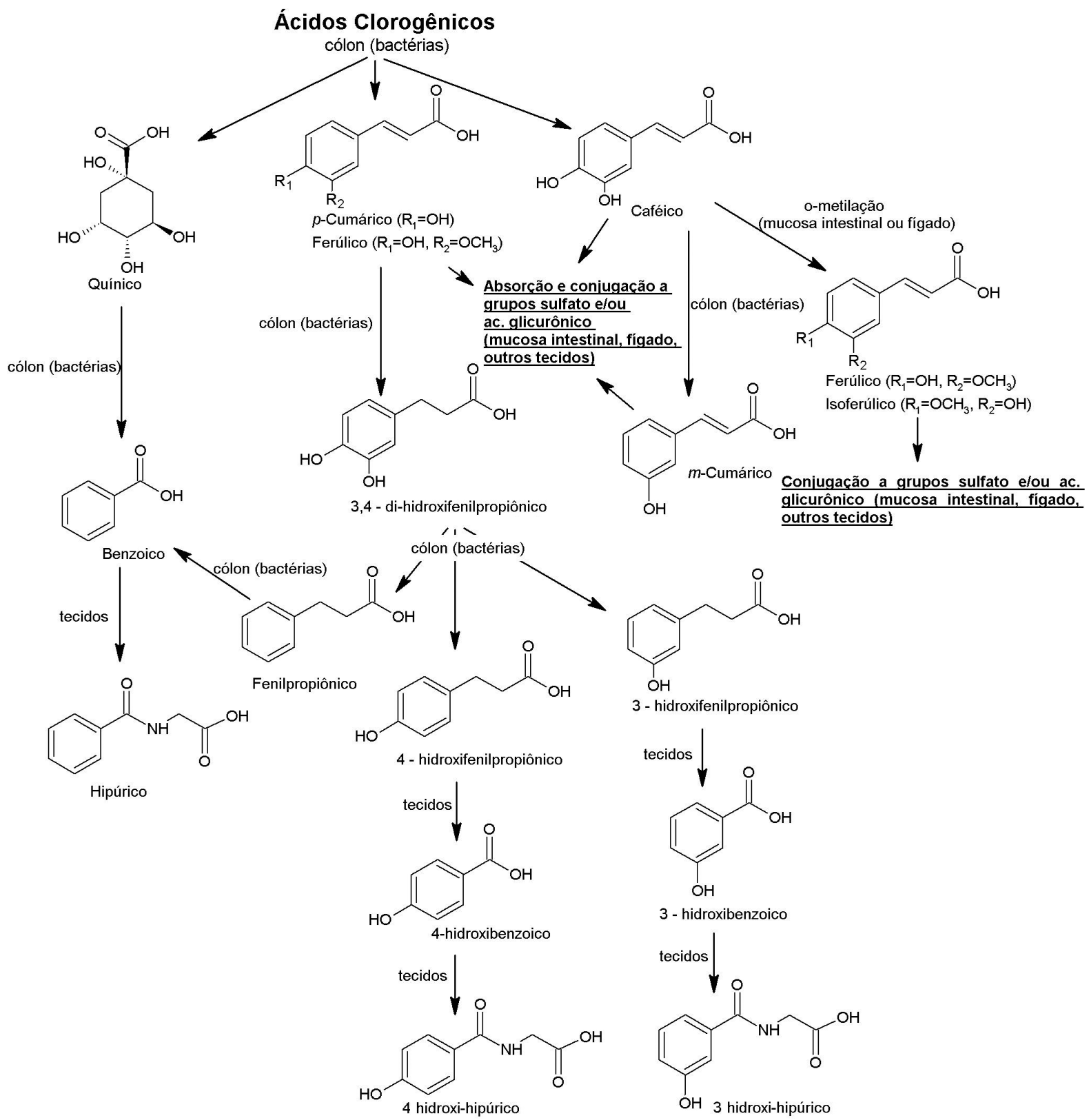

Figura 4. Representação esquemática das vias gerais de metabolismo dos ácidos clorogênicos 
ácido benzoico ${ }^{39} \mathrm{O}$ ácido hipúrico é um dos principais metabólitos encontrados na urina após a ingestão de ácidos clorogênicos. ${ }^{35,38}$

O ácido vanílico, outro metabólito encontrado no plasma e urina de humanos após o consumo de alimentos ricos em ácidos clorogênicos resulta da redução do ácido ferúlico, sendo transformado em ácido di-hidroferúlico, que, ao sofrer $\beta$-oxidação, origina o ácido vanílico. $^{34-36,41}$

A Figura 4 ilustra a via geral de metabolização dos ácidos clorogênicos, proposta com base no conhecimento que se tem até o momento acerca dos metabólitos formados. Muitos destes compostos são comuns ao metabolismo de flavonoides, como as catequinas, flavononas (hesperitina, naringerina) e proantocianidinas, os quais têm sua estrutura clivada pela microflora colônica, dando origem a ácidos fenólicos. ${ }^{10,14}$

Apesar dos avanços recentes, não existe ainda um consenso sobre a biodisponibilidade relativa dos ácidos clorogênicos, ou seja, a porcentagem da quantidade ingerida que efetivamente é absorvida e metabolizada, principalmente pela falta de dados consistentes sobre seus metabólitos, mormente no que se refere à quantificação em tecidos. Em indivíduos com ileostomia, 33\% de um total de 1000 $\mathrm{mg}(2,8 \mathrm{mmol})$ de 5-CQA isolado foram absorvidos, baseando-se na quantidade recuperada no fluido da ileostomia. Menos de $1 \%$ do 5-CQA absorvido foi encontrado intacto na urina. Em outro estudo com humanos com cólon intacto, 1,7\% de $2 \mathrm{~g}$ (5,5 mmol) de 5-CQA estavam presentes na urina. ${ }^{39} \mathrm{Em}$ estudo com animais, que receberam durante 8 dias em média 73,6 mg/dia (208,7 $\mu \mathrm{mol} /$ dia $)$ de 5-CQA adicionado à ração, as quantidades de 5-CQA na urina foram semelhantes à dos estudos em humanos, cerca de $1 \% .^{38}$

No entanto, quando levados em conta os metabólitos formados pela ação de enzimas endógenas e/ou da microflora intestinal, até $36 \%^{39} \mathrm{e}$ $58 \%{ }^{38}$ destas doses ingeridas foram recuperadas na urina. Em um estudo com humanos que ingeriram $400 \mathrm{mg}$ de extrato de café contendo 170 mg (451 $\mu \mathrm{mol})$ de ácidos clorogênicos, de 7,8 a 72\% da dose ingerida foi encontrada no plasma, levando em conta alguns metabólitos. ${ }^{42}$ No entanto, as quantidades encontradas no plasma não corresponderam à excreção urinária, ${ }^{42} \mathrm{o}$ que leva a crer que os metabólitos quantificados podem não corresponder a todos aqueles produzidos a partir dos ácidos clorogênicos presentes no extrato ingerido.

Para compreender os mecanismos de ação dos compostos fenólicos em geral, além de identificar e quantificar os metabólitos formados, é necessário identificar os tecidos alvos em que se depositam. ${ }^{8}$ Dados sobre concentrações teciduais de compostos fenólicos são escassos e, no caso de ácidos clorogênicos, inexistentes até o momento.

$\mathrm{O}$ avanço das pesquisas que avaliam a relação entre o consumo de vegetais e CBAs e a modulação de processos oxidativos, infamatórios e mutagênicos em organismos vivos depende da elucidação da rota de metabolização desses compostos, assim como o estabelecimento de níveis necessários e/ou seguros de ingestão depende também de se estabelecer de que forma esses compostos são transformados e como se encontram nos diferentes tecidos e fluidos biológicos. $\mathrm{O}$ desenvolvimento de técnicas de biologia molecular e o acesso mais fácil a ferramentas como a espectrometria de massas está permitindo um avanço significativo nesta área. Ainda assim, é provável que mais uma década seja necessária para o estabelecimento de biomarcadores e níveis de ingestão para compostos fundamentais para a manutenção da saúde, dadas a complexidade da matriz alimento, a variabilidade individual e a decisiva ação da microbiota intestinal na metabolização de compostos fenólicos.

\section{REFERÊNCIAS}

1. Bastos, D. H. M.; Rogero, M. M.; Arêas, J. A. G.; Arq. Bras. Endocrinol. Metab. 2009, 53, 646.
2. Holst, B.; Williamson, G.; Curr. Opin. Biotechnol. 2008, 19, 73.

3. Spencer, J. P.; Abd, E. 1.; Mohsen, M. M.; Minihane, A. M.; Mathers, J. C.; Br. J. Nutr. 2008, 99, 12.

4. D'Archivio, M.; Filesi, C.; Di Benedetto, R.; Gargiulio, R.; Giovannini, C.; Masella, R.; Ann. Ist. Super Sanitá 2007, 43, 348.

5. Kussmann, M.; Affolter, M.; Nagy, K.; Holst, B.; Fay, L. B.; Mass Spec. Rev. 2007, 26, 727

6. Scalbert, A.; Williamson, G.; J. Nutr. 2000, 130, 2073.

7. Williamson, G.; Manach, C.; Am. J. Clin. Nutr. 2005, 81, 243 S.

8. Crozier, A.; Jaganath, I. B.; Clifford, M. N.; Nat. Prod. Rep. 2009, 26, 1001.

9. Kroon, P. A.; Clifford, M. N.; Crozier, A.; Day, A. J.; Donovan, J. L.; Manach, C.; Williamson, G.; Am. J. Clin. Nutr. 2004, 80, 15.

10. Manach, C.; Williamson, G.; Morand, C.; Scalbert, A.; Rémésy, C.; Am. J. Clin. Nutr. 2005, 81, 230S.

11. Scholz, S.; Williamson, G.; Int. J. Vitam. Nutr. Res. 2007, 77, 224.

12. Williamson, G.; Holst, B.; Br. J. Nutr. 2008, 99, S55.

13. Robbins, R.; J. Agric. Food Chem. 2003, 51, 2866.

14. Manach, C.; Scalbert, A.; Morand, C.; Rémésy, C.; Jimenez, L.; Am. J. Clin. Nutr. 2004, 79, 727.

15. Clifford, M. N.; J. Sci. Food Agric. 1999, 70, 362.

16. Lafay, S.; Gil-Izquierdo, A.; Phytochem. Rev. 2008, 7, 301.

17. Karakaya, S.; Crit. Rev. Food Sci. Nutr. 2004, 44, 453.

18. Bourne, L. C.; Rice-Evans, C.; Biochem. Biophys. Res. Commun. 1998, 253, 222.

19. Bastos, D. H. M.; Oliveira, D. M.; Matsumoto, R. L. T; Carvalho, P. O.; Ribeiro, M. L.; Med. Aromatic Plant Sci. Biotechnol. 2007, 1, 37.

20. Clifford, M. N.; J. Sci. Food Agric. 2000; 80, 1033.

21. De Maria, C. A. B.; Moreira, R. F. A.; Quim. Nova 2004, 27, 586.

22. Canela, M. D.; Bastos, D. H. M.; Pinheiro, M. M.; Ciconelli, R.; Ferraz, M. B.; Martini, L.; Nutrire 2009, 34, 143.

23. Bastos, D. H. M.; Fornari, A. C.; Queiroz, Y. S.; Torres, E. A. F.; Braz. Arch. Biol. Technol. 2006, 49, 399.

24. Bastos, D. H. M.; Saldanha, L. A.; Catharino, R. R.; Sawaya, H. F.; Cunha, I. B. S.; Carvalho, P. O.; Eberlin, M. N.; Molecules 2007, 12, 423.

25. Oliveira, D. M.; Freitas, H. S.; Souza, M. F. F.; Arçari, D. P.; Ribeiro, M. L.; Carvalho, P. O.; Bastos, D. H. M.; J. Agric. Food Chem. 2008, 56,10527

26. Bastos, D. H. M.; Fornari, A. C.; Queiroz, Y. S.; Manólio, R. A.; Torres, E. A. F.; Acta Farm. Bonaerense 2005, 24, 91.

27. Macheix, J. J.; Fleuriet, A.; Billot, J.; Fruit Phenolics, CRC Press: Boca Raton, 1990.

28. Morais, J. A. G.; Lobato, M. R.; Basic Clin. Pharmacol. Toxicol. 2010, 106, 221.

29. Azuma, K.; Ipposushi, K.; Nakayama, M.; Ito, H.; Higashio, H.; Terao, J.; J. Agric. Food Chem. 2000, 48, 5496.

30. Olthof, M. R.; Hollman, P. C; Katan, M. B.; J. Nutr. 2001, 131, 66.

31. DuPont, M. S.; Bennet, R. N.; Mellon, F. A.; Williamson, G.; J. Nutr. 2002, 132, 172.

32. Konishi, Y.; Zhao, Z.; Shimizu, M.; J. Agric. Food Chem. 2006, 54, 7539.

33. Nardini, M.; Cirillo, E.; Natella, F.; Scaccini, C.; J. Agric. Food Chem. 2002, 50, 5735

34. Rechner, A. R.; Pannala, A.; Rice-Evans, C. A.; Free Radical Res. 2001, 35, 195.

35. Rechner, A. R.; Spencer, J. P. E.; Kuhnle, G.; Hahn, U.; Rice-Evans, C. A.; Free Radical Biol. Med. 2001, 30, 1213.

36. Rechner, A. R.; Kuhnle, G.; Bremner, P.; Hubbard, G. P.; Moore, K. P.; Rice-Evans, C. A.; Free Radical Biol. Med. 2002, 33, 220.

37. Cremin, P.; Kasim-Karakas, S.; Waterhouse, A. L.; J. Agric. Food Chem. 2001, 49, 1747.

38. Gonthier, M. P.; Verny, M. A.; Besson, C.; Remesy, C.; Scalbert, A.; J. Nutr. 2003, 133, 1853. 
39. Olthof, M. R.; Hollman, P. C; Buijsman, M. C. N. P.; Amelsvoort, J. M. M.; Katan, M. B.; J. Nutr. 2003, 133, 1806.

40. Yang, B.; Meng, Z.; Dong, J.; Yan, L.; Zou, L.; Tang, Z.; Dou, G.; Drug. Metab. Dispos. 2005, 33, 930.

41. Monteiro, M.; Farah, A.; Perrone, D.; Trugo, L. C.; Donangelo, C.; J. Nutr. 2007, 137, 2196.

42. Farah, A.; Monteiro, M.; Donangelo, C. M.; Lafay, S.; J. Nutr. 2008, 138, 2309.

43. Lafay, S.; Gil-Izquierdo, A.; Manach, C.; Morand, C.; Besson, C.; Scalbert, A.; J. Nutr. 2006, 136, 1192.

44. Plumb, G. W.; Garcia-Conesa, M. T.; Kroon, P. A.; Rhodes, M.; Ridley, S.; Williamson, G.; J. Sci. Food Agric. 1999, 79, 390.
45. Adam, A.; Crespy, V.; Levrat-Verny, M. A.; Leenhardt, F.; Leuillet, M.; Demign'e, C.; Remesy, C.; J. Nutr. 2002, 132, 1962.

46. Konishi, Y.; Kobayashi, S.; J. Agric. Food Chem. 2004, 52, 2518.

47. Iwanaga, T.; Takebe, K.; Kato, I.; Karaki, S. I .; Kuwahara, A.; Biomed. Res. 2006, 27, 243.

48. Rondini, L.; Peyrat-Maillard, M. N.; Marsset-Baglieri, A.; Berset, C.; J. Agric. Food Chem. 2002, 50, 3037.

49. Ito, H.; Gonthier, M.; Manach, C.; Morand, C.; Mennen, L.; Rémésy, C.; Scalbert, A.; Br. J. Nutr. 2005, 94, 500

50. Mateos, R.; Goya, L.; Bravo, L.; J. Agric. Food Chem. 2006; 54, 8724.

51. Zhao, Z.; Egashira, Y.; Sanada, H.; J. Nutr. 2004, 134, 3083. 